\title{
On Assessing Emotional Intelligence as a Precursor of Positive Personality Functioning and Mental Health
}

\author{
Alina Chetveryk-Burchak \\ Ph.D. student, Department of Educational and Developmental Psychology, \\ Oles Honchar Dnipropetrovsk National University, \\ Dnipropetrovsk, Ukraine \\ yaneznau@list.ru \\ Eleonora Nosenko \\ Chairperson of the Department of Educational and Developmental Psychology, \\ Oles Honchar Dnipropetrovsk National University, \\ Dnipropetrovsk, Ukraine
}

\begin{abstract}
The recent conceptualization of emotional intelligence (EI) as a new dynamic integral trait (Austin et al., 2008; Ziedner et al., 2009) and "a wise management of emotions" (Nosenko, 2011) has opened up prospects for the comprehensive assessment of its role in positive personality functioning. The objective of this paper is to present empirical findings (obtained on a sample of 135 participants) which show that the individuals with high levels of EI are characterized by positive behavioral outcomes, indicative of their mental health continuum (Keyes, 2002) and achievements in the fulfillment of the basic life tasks (Janakov, 2008). The findings are claimed to help solving the controversy of the ability/trait conceptualization of EI.
\end{abstract}

Keywords: emotional intelligence, ability/trait controversy, mental health, positive functioning.

\section{INTRODUCTION}

A wide diversity of aspects identified in the phenomenon of emotional intelligence (EI) within a comparatively short period of time, since the term had appeared in the psychological thesaurus, made EI one of the most attractive phenomena for studying the personality precursors of the individual's optimal functioning. As is known, EI was conceptualized first as a set of abilities to adequately perceive, understand and manage emotions, which can be exercised both intrapersonally and interpersonally (Mayer \& Salovey, 1990). Then it was interpreted as an array of non-cognitive capabilities, competences and skills that influence one's ability to succeed in coping with environmental demands and pressures (Goleman, 1995; Bar-On, 1997). The global personality traits were defined as dispositional components (Petrides \& Furnham, 2001).

Numerous findings prove that EI is associated with life success, leadership abilities, life satisfaction, subjective well-being, self-actualization, adaptability. At the same time, the question still remains, whether EI is a precursor of positive personality functioning or on the contrary an outcome of the positive latter. This question can now be discussed more comprehensively thanks to the new approaches to the conceptualization of the construct that were identified lately. Contemporary personality psychologists have realized that operationalization of personality as a relatively small number of traits, measured by 
questionnaires, may fail to illuminate important aspects of the personality sphere. As the editors of the recently published SAGE Handbook of "Personality Theory and Assessment" (Boyle et al.,2008) point out, the new personality trait and dynamic trait constructs can be found at the interface of the personality and ability, personality and values, personality and beliefs, which allow to assess personality functioning more comprehensively and adequately. In the review of the current research findings, related to studying EI, Austin et al. (2008) claim that while the "trait EI" allows its operationalization as an explicit aspect of personality that can be measured by questionnaires, the EI as a true ability requires implicit assessment with the help of the objective tests and behavioral measures. But there are no reliable instruments to assess EI as an ability and its correlations with general intelligence are only moderate and do not exceed 0.3 .

The authors of the recently published monograph on EI (Zeidner et al., 2009) have included into its foreword, written by James R. Averill, the Aristotel's famous definition of some individual's ability to manage their emotions wisely as a virtue. The first variant of translation of the term EI into Ukrainian language made by one of the authors of this paper (E. Nosenko, 2003) was formulated as "a wise management of emotions" ("rozumnist") reflecting the Aristotel's idea of the personality's virtuous behavior.

The objective of this paper was to demonstrate that EI, evaluated explicitly (as a trait) appears to be indicative of the mental health, assessed with the help of a new technique "The Mental Health Continuum - Short Form MHC-SF" (Keyes, 2009) which allows to define the frequency of experiencing some likely "consequential outcomes" of mental health in terms of the symptoms of psychological, social and emotional well-being.

\section{EXISTING RESEARCH FINDINGS}

There are convincing empirical findings that reflect the role of EI in determining mental and physical health of an individual (Zeidner et al., 2009). Evidence has also been gathered concerning the role of the high level of EI in preventing the development of maladaptive emotional states associated with mood and anxiety disorders. Current research findings show that the individuals with higher level of EI typically experience more positive moods and are better able to repair a negative mood after its induction (Schutte et al., 2002).

Lack of awareness of emotions and the inability to manage them are reported to be key symptoms in some personality disorders and impulse control disorders (Matthews et al., 2002). Schutte et al. (1998) found that lower level of emotional intelligence was associated with more alexithymia and less impulse control while higher level of EI is linked with aspects of better psychosocial functioning (e.g., Brown \& Schutte, 2006; Salovey\& Grewal, 2005; Schutte et al., 1998; Schutte et al., 2001) and greater optimism. Some of psychosocial factors, such as more social support and more satisfaction with social support, are claimed (Brown \& Schutte, 2006) to serve as buffers to physical illness.

The low EI college students, males in particular, have been reported to be at risk for potentially harmful behaviors, such as addiction to the illegal drugs, excessive consumption of alcohol, and engaging in deviant behavior (Brackett et al. 2004). There are data that also point to modest correlation in a sample of adults between EI and alcohol and drug problems (Riley \& Schutte 2003).

A meta-analytic investigation of the relationship between emotional intelligence and health (Schutte et al., 2007), based on the responses of 7898 participants, yielded the results, proving 
that EI was significicantly and positively related to different types of health indicators: with $r=.29$ for mental health (anxiety, depresion), $r=.31-$ for psychosomatic health, and $r=.22$ for physical health. Individuals with higher EI appeared to report fewer clinical symptoms, including: anxiety (O'Connor \& Little 2003), depression (Saklofske et al. 2003), loneliness (Engelberg \& Sjoberg 2004), and the signs of the borderline personality (Leible \& Shell 2004). In addition to the above reviewed findings, it was found out that men with lower EI have been engaged in self-destructive behavior (Brackett et al. 2004).

\section{SUBSTANTIATION OF METHOLOGY OF THIS RESEARCH}

This research is based on the hierarchical informational-proceeding model of EI suggested by Nosenko and Kovriga (2003) that presumes three levels of EI development.

The low level of EI is characterized by the generation of the impulsive, emotional responses to the external stimuli. This type of emotional responses reflects mechanisms of the conditioned reflex, i.e. they are initiated at the sensory-perceptual level (not mediated by the thinking). The modality of emotions is consistent with that of the stimulus.

The intermediate level of EI is characterized by the generation of responses mediated by thinking. So, the individuals deliberately select the types of responses, the modalities of which might not coincide with the modalities of the stimuli.

The highest level of EI reflects the developed inner world of an individual. The activity is based on the system of sets that reflect the internalized norms of behavior to which the individual habitually sticks, not experiencing inner tension. It enables the activity on the "suprasituational" level, free of contextual constraints. Thus, on the highest level of EI development the behavior is controlled automatically (by the internalized system of individual beliefs as to the rules and norms of appropriate behavior).

The present study is based on the conceptualization of EI as an integral dynamic trait. This empirical research was designed to answer the following questions:

- Do individuals, who achieved higher levels of EI demonstrate higher levels of the mental health continuum, the latter being indicative of EI?

- Do individuals with higher levels of the EI development possess more adaptive dispositional personality traits, which thus reflect their positive functioning?

- Do individuals with higher levels of the EI development have higher levels of self-esteem, purpose in life and satisfaction with life, which confirm that EI is rather an integral dynamic trait than an emotional ability?

\section{METHOD}

\section{Participants}

The sample consisted of 135 adults (65 male and 75 female) aged from 18 to 35 years. The participants were the office employees (44.5\%), students of National Mining University (38.5 $\%)$ and students of Oles Honchar Dnipropetrovsk National University (17 \%). Participants were not paid for their services but upon request could receive an individual feedback via email one to two months after they finished the study.

\section{Data tools}

To answer the research questions the following data tools were chosen. "EMIN" (Lyusin D, 2009 ) is a questionnaire designed for the self- assessment of emotional intelligence. It consists of 46 items with a four-point Likert scale $(0=$ strongly disagree; $1=$ moderately disagree; $2=$ moderately agree; 3 = strongly agree). The Cronbach's alpha values for the scales are $>.80$. 
"Four Factor Test of Social Intelligence" (M. O'Sullivan \& J. P. Guilford, 1976) is an instrument which consists of 4 subtests (Cartoon Prediction, Expression Grouping, Social Translation, Cartoon Missing) and measures social intelligence. Russian version of the test was adapted by E. S. Mihajlova (1990). Internal validity values of the subtests are in the range from .66 to .73.

"The Big Five Locator" (Howard et al., 1996) is an instrument designed to assess the personality traits of an individual. The Ukrainian version was adapted by L. Burlachuk and D. Korolo'v (2000). The inventory consists of 25 adjectives and measures five personality traits: Extraversion, Openness to Experience, Agreeableness, Neuroticism, and Consciousness. Cronbach's alpha values are .73 for Introversion, .55 for Neuroticism, .70 for Consciousness, .41 for Openness to Experience and .63 for Agreeableness.

"The Mental Health Continuum - SF" (Keyes, 2009) is a self-report questionnaire that consists of 14 items, measuring hedonic well-being, symptoms (items 1-3) and positive functioning symptoms (items 4-8 which are indicators of social well-being and 9-14 indicators of psychological well-being). Mental health continuum is indicated when a set of symptoms at a specific level are present for a specific duration. The Ukrainian version of the "MHC-SF-UA" was adapted by E. Nosenko and A. Chetveryk-Burchak (2014) at the consent of the author. Cronbach's alpha value was 853.

The Satisfaction with Life Scale - SWLS (Diener et al., 1985) is a short 5-item instrument designed to measure global cognitive judgments of satisfaction with one's life. SWLS has a 7point Likert scale ranging from 1 (strongly disagree) to 7 (strongly agree). A total score is calculated by summing the individual responses. The Russian version of the SWLS was adapted by E. N. Osin and D. A. Leont'ev (2008). Cronbach's alpha value was .75.

"Coping Inventory for Stressful Situations" (Endler \& Parker, 1990). It consists of 48 items, responses being measured on a five-point Likert scale (from 1 - never to 5 - very often). The Russian version of CISS was adapted by T. Kryukova (2001). Cronbach's alpha were 853 (taskoriented coping), .877 (emotion-oriented coping) and .814 (avoidance-oriented coping).

Rosenberg Self-Esteem Scale - RSES (Rosenberg, 1965) is a questionnaire designed for measuring global self-esteem. It consists of 10 items, responses being measured on a fourpoint Likert scale (from 1 - strongly disagree to 4 - strongly agree). The adaptation of the Russian version of the scale was presented by L. F. Burlachuk and S. M. Morozov (1989). Cronbach's alpha value was .72.

Purpose-in-life Test (Crumbaugh \& Maholick, 1981) is an instrument developed to assess meaning and purpose in life. It consists of 20 items, each rated on a 7-point scale ranging from 1 (low porpose) to 7 (high porpose). Russian version of the PIL was adapted by D. A. Leont'ev (2000). Scores are obtained for 5 subscales: purpose in life, emotional richness of life, satisfaction with self-actualization, locus of self-control and locus-control of life.

\section{Procedure}

With the help of the method of cluster analysis (K-means algorithm) the sample of participants was split into three groups on the variables of emotional intelligence, social intelligence and Big five personality trait variables (extraversion, neuroticism, openness to experience, agreeableness and conscientiousness) as indicative of the dispositional components of EI. After that the between-cluster differences were computed and the differences were assessed by ttest. 
Participants were contacted in person or via e-mail. They expressed an interest in participating in the study and had given contact details for future use.

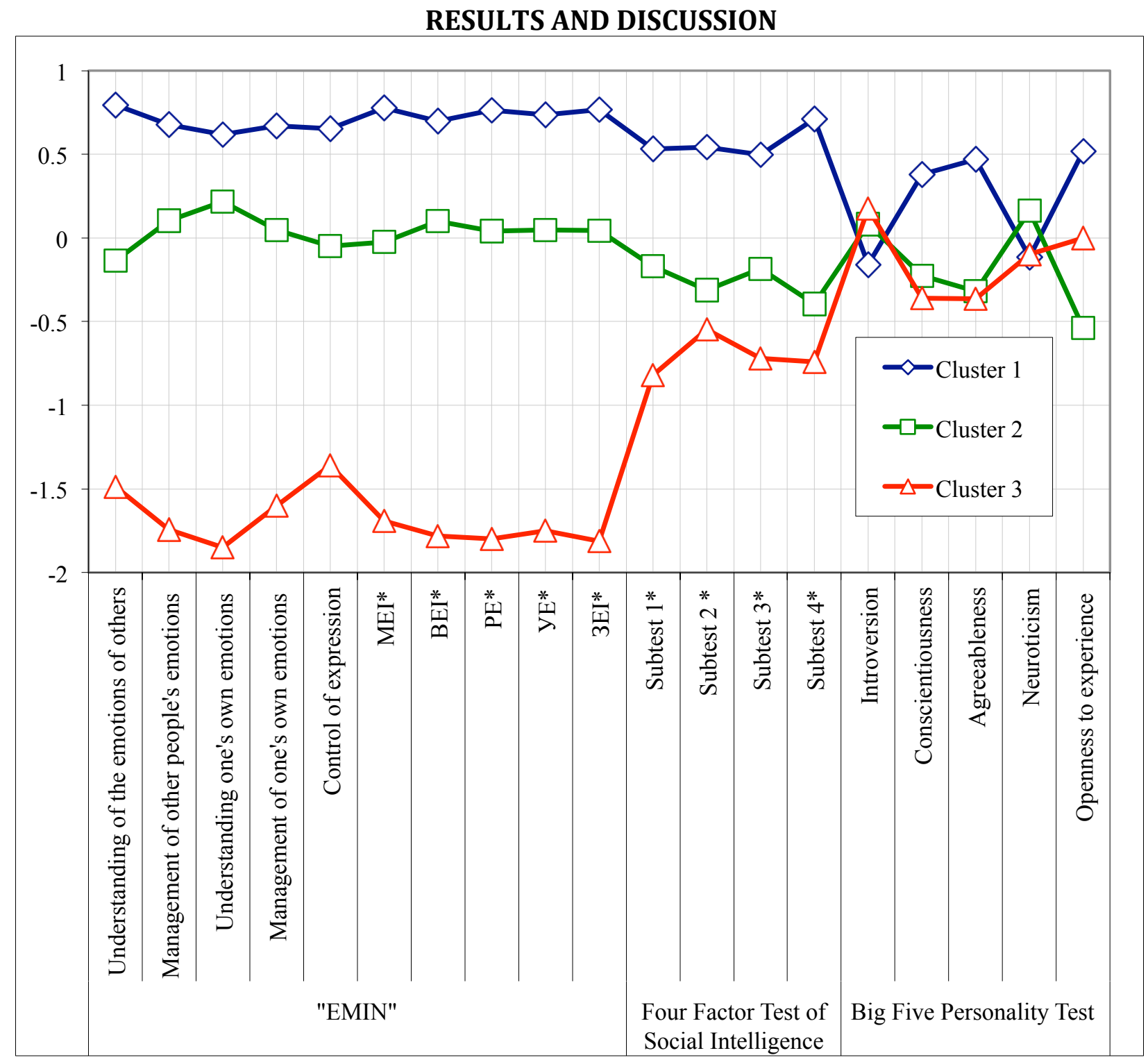

Figure 1: The results of clusterization of the sample

* MEI - inter-personal emotional intelligence; BEI - intra-personal emotional intelligence; PE understanding of emotions; $\mathrm{YE}$ - management of emotions; 3EI -general score of emotional intelligence.

Subtest 1 - ability to understand consequences of behavior; Subtest 2 - ability to understand nonverbal information; Subtest 3 - ability to understand the content of the words according to the character of interpersonal interaction; Subtest 4 - ability to understand the logic of the complicated situations of interaction.

Differences between the variables, used for clusterization, were processed with the help of ttest (see Tables 1, 2).

Table 1 shows between-cluster differences in the cumulative scores of the emotional intelligence. 
Table 1: Between-cluster (1 $\left.{ }^{\text {st }} v s .3^{\text {rd }}\right)$ differences in Emotional Intelligence Variables

\begin{tabular}{|c|c|c|c|c|c|}
\hline Variables & $\begin{array}{c}\text { Mean } \\
\text { Cluster } 1(\mathrm{~N}= \\
56)\end{array}$ & $\begin{array}{c}\text { Mean } \\
\text { Cluster } 3(\mathrm{~N}= \\
25)\end{array}$ & t-value & $\begin{array}{l}\text { Std. Dev. } \\
\text { Cluster } 1\end{array}$ & $\begin{array}{l}\text { Std. Dev. } \\
\text { Cluster } 3\end{array}$ \\
\hline $\begin{array}{l}\text { Understanding other people } \\
\text { emotions }\end{array}$ & 35,67 & 22,36 & $18,09 * *$ & 2,50 & 4,05 \\
\hline $\begin{array}{l}\text { Management of other people } \\
\text { emotions }\end{array}$ & 29,51 & 16,88 & $18,99 * *$ & 1,17 & 4,69 \\
\hline $\begin{array}{l}\text { Understanding one's own } \\
\text { emotions }\end{array}$ & 28,96 & 15,28 & $23,39 * *$ & 1,67 & 3,61 \\
\hline $\begin{array}{l}\text { Management of one's own } \\
\text { emotions }\end{array}$ & 20,62 & 12,24 & $16,42 * *$ & 1,49 & 3,11 \\
\hline Control of expression & 18,73 & 11,16 & $12,26 * *$ & 2,18 & 3,27 \\
\hline $\begin{array}{l}\text { Inter-personal emotional } \\
\text { intelligence }\end{array}$ & 65,19 & 39,24 & $21,91 * *$ & 3,05 & 7,64 \\
\hline $\begin{array}{l}\text { Intra-personal emotional } \\
\text { intelligence }\end{array}$ & 68,32 & 38,68 & $22,79 * *$ & 4,14 & 7,54 \\
\hline Understanding of emotions & 64,64 & 37,64 & $29,67 * *$ & 3,19 & 4,87 \\
\hline Management of emotions & 68,87 & 40,28 & $22,87 * *$ & 3,53 & 7,75 \\
\hline $\begin{array}{l}\text { General score of emotional } \\
\text { intelligence } \\
* * p<.001\end{array}$ & 133,51 & 77,92 & $28,70 * *$ & 6,30 & 11,06 \\
\hline
\end{tabular}

Table 2: Between-cluster (1 $1^{\text {st }}$ vs. $\left.3^{\text {rd }}\right)$ differences in social intelligence and personality trait variables

\section{Variables}

Subtest 1 (ability to understand consequences of behavior ("cartoon prediction"))

Subtest 2 (ability to understand non-verbal information ("expression grouping"))

Subtest 3 (ability to understand content of the words according to character of inter-personal interaction ('social translation"))

Subtest 4 (ability to understand the logic of complicated situations of interaction ("missing cartoons))

Introversion

Conscientiousness

Agreeableness

Neuroticism

Openness to experience

$* * * \mathrm{p}<.01 ; * * \mathrm{p}<.001$

\begin{tabular}{|c|c|c|c|c|}
\hline $\begin{array}{c}\text { Mean } \\
\text { Cluster } 1 \\
(\mathrm{~N}=56)\end{array}$ & $\begin{array}{c}\text { Mean } \\
\text { Cluster } 3 \\
(\mathrm{~N}=25)\end{array}$ & t-value & $\begin{array}{l}\text { Std. Dev. } \\
\text { Cluster } 1\end{array}$ & $\begin{array}{l}\text { Std. Dev. } \\
\text { Cluster } 3\end{array}$ \\
\hline 10,50 & 7,04 & $7,09 * *$ & 1,87 & 2,33 \\
\hline 8,42 & 6,04 & $5,10^{* *}$ & 1,92 & 1,98 \\
\hline 8,96 & 6,08 & $5,81^{* *}$ & 1,91 & 2,36 \\
\hline 7,50 & 4,12 & $7,06 * *$ & 2,14 & 1,58 \\
\hline 22,03 & 23,68 & $-1,33$ & 4,53 & 6,26 \\
\hline 34,75 & 31,12 & $3,33^{* *}$ & 3,44 & 6,34 \\
\hline 30,96 & 27,08 & $3,79 * *$ & 4,65 & 1,30 \\
\hline 19,33 & 19,44 & $-0,07$ & 6,25 & 1,19 \\
\hline 29,67 & 23,35 & $2,63 * * *$ & 5,46 & 1,36 \\
\hline
\end{tabular}


As shown in Table 2, the opposite clusters (1 and 3) significantly differed on all the four variables of social intelligence and on the dispositional trait variables: conscientiousness, agreeableness and openness to experience. There no significant differences only on neuroticism and introversion.

The participants' data demonstrated that the chosen sample included $41.5 \%(\mathrm{~N}=56)$ of individuals with a high level of emotional intelligence, $40 \%(\mathrm{~N}=54)$ - with an average level, and $18.5 \%(\mathrm{~N}=25)$ - with an extremely low level of emotional intelligence.

To examine the relationship between emotional intelligence and mental health, betweencluster differences were compared with mental health indicators and other variables which were chosen as likely dependent variables of the quasi-experiment for non-equivalent groups (Table 3).

Table 3: Between-cluster (1 ${ }^{\text {st }} v$ s. $3^{\text {rd }}$ ) differences in the dependent variables of the quasi-experiment for

Variables

$\quad$ Variables
Mental Health
Purpose in Life
Emotional richness of life
Satisfaction with self-actualization
Locus of self-control
Locus control of life
Purpose in Life (general point)
Self-Esteem
Satisfaction with life
Task-oriented coping
Emotion-oriented coping
Avoidance-oriented coping
$* * * p<.01 ; * *$ p $<.001$

$* * * \mathrm{p}<.01 ; * * \mathrm{p}<.001$ non-equivalent groups.

$\begin{array}{ccccc}\begin{array}{c}\text { Mean } \\ \text { Cluster 1 } \\ (\mathrm{N}=56)\end{array} & \begin{array}{c}\text { Mean } \\ \text { Cluster } 3 \\ (\mathrm{~N}=25)\end{array} & \text { t-value } & \begin{array}{c}\text { Std. Dev. } \\ \text { Cluster } 1\end{array} & \begin{array}{c}\text { Std. Dev. } \\ \text { Cluster 3 }\end{array} \\ 50,08 & 41,84 & \mathbf{3 , 3 6 * *} & 9,93 & 10,72 \\ 34,64 & 27,08 & \mathbf{6 , 1 0 * *} & 4,60 & 6,21 \\ 32,92 & 29,12 & \mathbf{3 , 4 7 * *} & 4,64 & 4,33 \\ 27,92 & 23,68 & \mathbf{4 , 3 5 * *} & 3,83 & 4,52 \\ 22,94 & 18,76 & \mathbf{3 , 7 6 * *} & 4,35 & 5,19 \\ 32,66 & 21,76 & \mathbf{8 , 7 0 * *} & 4,87 & 5,90 \\ 111,01 & 93,72 & \mathbf{5 , 4 3 * *} & 12,79 & 14,16 \\ 33,37 & 29,36 & \mathbf{4 , 9 4 * *} & 3,36 & 3,41 \\ 23,69 & 20,52 & \mathbf{2 , 6 2 * * *} & 4,62 & 5,84 \\ 61,08 & 51,24 & \mathbf{4 , 7 7 * *} & 6,66 & 11,83 \\ 41,01 & 46,68 & \mathbf{2 , 1 1 * * *} & 10,91 & 11,57 \\ 48,73 & 47,84 & 0,35 & 11,03 & 8,61\end{array}$

The first cluster with the highest levels of the clusterization variables (analogues of the independent variables) appeared to show the highest levels of mental health as well as most of other variables chosen to represent the likely behavioral consequences of different levels of EI, conceptualized as an integral dynamic trait, indicative of the positive functioning and mental health continuum. The participants of the first cluster have significantly higher value of the task-oriented coping $(\mathrm{t}=4.77)$ and significantly lower emotion-oriented coping, while differences in the avoidance-oriented coping are not significant. These and other results provide the convincing answers to our research questions to be commented upon later in thus section of the paper. Table 4 shows significant differences not only between the "opposite" clusters of the participants ( 1 and 3 ), but also between the clusters with the highest and the intermediate levels of EI.

As shown in Table 4, the representatives of the cluster with the high level of EI have significant differences in mental health, five subscales of the Purpose-in-Life Test, they are more satisfied with life, have higher level of self-esteem and tend to use task oriented coping strategy as compared against the individuals of the cluster with the intermediate level of emotional 
intelligence. So, the data obtained in this research provide answers to all four research question.

Table 4: Between-cluster (1st vs. $\left.{ }^{\text {nd }}\right)$ differences in the dependent variables.

\begin{tabular}{lccccc}
\multicolumn{1}{c}{ Variables } & $\begin{array}{c}\text { Mean } \\
\text { Cluster 1 } \\
(\mathrm{N}=56)\end{array}$ & $\begin{array}{c}\text { Mean } \\
\text { Cluster 2 } \\
(\mathrm{N}=54)\end{array}$ & t-value & $\begin{array}{c}\text { Std. Dev. } \\
\text { Cluster 1 }\end{array}$ & $\begin{array}{c}\text { Std. Dev. } \\
\text { Cluster 3 }\end{array}$ \\
Mental Health Continuum & 50.08 & 41.01 & $\mathbf{4 . 1 9 * *}$ & 9.93 & 12.61 \\
Purpose in Life & 34,64 & 31,29 & $\mathbf{2 . 8 9 * * *}$ & 4.60 & 7.35 \\
Emotional richness of life & 32,92 & 28,57 & $\mathbf{3 . 7 8 * *}$ & 4.64 & 7.18 \\
Satisfaction with self-actualization & 27,92 & 24,55 & $\mathbf{4 . 3 6 * *}$ & 3.83 & 4.25 \\
Locus of self-control & 22,94 & 20,37 & $\mathbf{3 . 1 9 * *}$ & 4.35 & 4.08 \\
Locus control of life & 32,66 & 29,07 & $\mathbf{3 . 5 4 * *}$ & 4.87 & 5.73 \\
Purpose in Life (general score) & 111,01 & 99,57 & $\mathbf{3 . 6 7 * *}$ & 12.79 & 19.34 \\
Self-Esteem & 33,37 & 31 & $\mathbf{3 . 5 3 * *}$ & 3.36 & 3.69 \\
Satisfaction with life & 23,69 & 20,40 & $\mathbf{3 . 7 2} * *$ & 4.62 & 4.63 \\
Task-oriented coping & 61,08 & 55,94 & $\mathbf{3 . 7 4 * *}$ & 6.66 & 7.72 \\
Emotion-oriented coping & 41,01 & 42,03 & $-0,49$ & 10.91 & 10.75 \\
Avoidance-oriented coping & 48,73 & 48 & 0.35 & 11.03 & 10.43
\end{tabular}

$* * * \mathrm{p}<.01 ; * * \mathrm{p}<.001$

In study 2 we included the Mental Health Continuum variable into the set of the analogues of independent variables, used in the first variant of clusterization, in order to test the incremental validity, if any, of the Mental Health Continuum as a likely criteria measure of EI. The data obtained with the help of cluster analysis (K-means algorithm) on the variables of EI, social intelligence, Big Five personality traits and the mental health continuum show that the tvalue differences (between $1^{\text {st }}$ and $3^{\text {rd }}$ clusters) appeared to be higher for all variables indicative of the positive functioning of an individual (purpose in life (6.34); emotional richness of life (4.50); satisfaction with self-actualization (5.10); life management 10.26; purpose in life (general score) (6.55); self-esteem (6.28); satisfaction with life (3.99); taskoriented coping 5.29) comparing with the results of explicit assessment of EI (as a trait).

\section{CONCLUSION}

The findings of the present study have provided answers to all the questions formulated before carrying out the empirical study. In answer to the first question we obtained data that proved the existence of differences in mental health between the opposite clusters both in case when MHC was included into the analysis as an additional independent variable and when it was analyzed as a dependent variable. This allows to conclude that MHC can be both a precursor of differences in EI and an outcome of the existing differences. So, its effect on EI might be reciprocal: high level of EI predisposes mental health, which, in its turn, causes the increase of EI. To answer the second question (about the effect of EI on the stable personality dispositions) we have obtained a partially controversial answer. The value of three of the five personality traits appeared to vary between the clusters in the predicted direction. The cluster with highly different levels of EI appeared practically not to differ on the level of neuroticism and introversion. It can be explained by the genetic roots of both: the neuroticism and extroversion/introversion, or probably by the fact that high level of EI influences the individual's shrewdness and makes the person very sensitive to the possible insincerity of other people which the person with very high level of EI may notice and the person with the low level of EI might overlook. In any case this aspect of the research requires further 
investigation. In answer to the third question we obtained data that proved that the high level of the emotional intelligence was strongly associated with greater life satisfaction, purpose in life, task-oriented coping and higher self-esteem. It confirms that EI is rather an integral dynamic trait than an emotional ability.

\section{References}

Austin, E. J., Parker, J.D.A., Petrides, K.V., \& Saklofske, D.H. (2008). Emotional intelligence. In G. J. Boyle, G. Matthews, \& D. H. Saklofske (Eds.), The SAGE handbook of personality theory and assessment: Vol 1. Personality theories and models (pp. 576-596). Thousand Oaks, CA: Sage Publications, Inc.

Bar-On, R. (1997). The Bar-On Emotional Quotient Inventory (EQ-i): Technical manual. Toronto, Canada: MultiHealth Systems.

Boyle G. J., Matthews G., \& Saklofske D. H. (Eds.). (2008) The SAGE handbook of personality theory and assessment: Vol 1. Personality theories and models (pp. 576-596). Thousand Oaks, CA: Sage Publications, Inc.

Brackett, M. A., Mayer, J.D., \& Warner, R. M. (2004). Emotional Intelligence and its relation to everyday behavior. Personality and Individual Differences 36, 1387-1402.

Brown, R. F., \& Schutte, N. S. (2006). Direct and indirect relationships between emotional intelligence and subjectivefatigue in university students. Journal of Psychosomatic Research, 60, 585-93.

Burlachuk, L. F., \& Morozov, S. M. (1989). The dictionary-directory on psychodiagnostics. Kiev: Scientific Thought.

Burlachuk L. F. \& Korolo'v D. K. (2000) An adaptation of the questionnaire for the assessment of the Big-Five personality traits. Questions of Psychology, 1, 126-134.

Diener, E., Emmons, R. A., Larsen, \& R. J., Griffin, S. (1985). The Satisfaction with Life Scale. Journal of Personality Assessment, 49, 71-75.

Endler, N. S., \& Parker, J. D. A. (1990). Coping Inventory for Stressful Situations (CISS): Manual.Toronto, Ontario, Canada: Multi-Health Systems.

Engelberg, E., \& Sjöberg, L. (2004a). Emotional intelligence, affect intensity, and social adjustment. Personality and Individual Differences, 37, 533-542.

Goleman, D. (1995) Emotional Intelligence. New York: Bantam books.

Janakov, B. (2008) Basic life tasks. Abstracts of the XXIX International Congress of Psychology, Berlin, Germany.

Guilford, J.P., \& O'Sullivan, M. (1976) Four Factor Test of Social Intelligence (Behavioral Cognition) Manual of Instructions and Interpretations. Orange, CA; Sheridan Psychological Services, Inc.

Crumbaugh, J. C., \& Maholick, L. T. (1981). Manual of instructions for the Purpose in Life test. Murfeesboro, TN: Psychometric Affiliates.

Howard, P.J., Medina, P.L., \& Howard, J. M. (1996) The big five locator: A quick assessment tool for consultants and trainers. In J. W. Pfeiffer (Ed.), The 1996 Annual: Vol. 1. Training. San Diego, CA: Pfeiffer and Company.

Keyes, C. L. M. (2002) The mental health continuum: From languishing to flourishing in life. Journal of Health and Social Behavior, 43, 207-222.

Keyes, C. L. M. (2009), "Atlanta: A Brief description of the Mental Health Continuum - Short Form (MHC-SF)", available at: www.sociology.emory.edu/ckeyes (accessed 26 January 2012).

Kryukova T. A. (2001) Adaptation of the questionnaire «Coping Inventory for Stressful Situations» (Endler, N. S., Parker, J. D. A.). Psychology and practice, 1, 70-82.

Leible, T., \& Snell, W. E., Jr. (2004). Borderline personality disorder and multiple aspects of emotional intelligence. Personality and Individual Differences, 37, 393-404.

Leont'ev, D.A. (2000) Purpose in Life Test (2 ${ }^{\text {nd }}$ edition). Moscow: Smysl. 
Burchak, A. C. \& Nosenko, E. (2014). On assessing emotional intelligence as a precursor of positive personality functioning and mental health. Advances in Social Sciences Research Journal, 1(4), 33-42

Lyusin, D.V. (2009) Emotional Intelligence inventory (EmIn): New psychometric data. In D.V. Lyusin, D.V. Ushakov, Social and emotional intelligence: From models to assessment (264-278). Moscow: Institute of Psychology Publishing.

Mattews, G., Zeidner, M., \& Roberts, R. D. (2002). Emotional Intelligence: Science and Myth. Cambridge: Bradford Book/ MIT Press.

Mayer, J., \& Salovey, P. (1990) Emotional intelligence. Imagination, Cognition, and Personality, 9, $185-211$.

Mihajlova, E. S. (1996) An instrument for the assessment of the social intelligence. SPb.: ADIS.

Nosenko, E. L., Arshava I.F., Kutovyi K. (2011). Implicit assessment of the emotional stability and wise management of emotions. Dnipropetrovs'k: "Innovation”.

Nosenko, E.L., Kovriga N.V. (2003) Emotional Intelligence: conceptualization of the phenomenon, major functions. Kyiv: "High School".

O’Connor, R. M., \& Little, I. S. (2003). Revisiting the predictive validity of emotional intelligence: Self-report versus ability-based measures. Personality and Individual Differences, 35, 1893-1902.

Osin, E. N., \& Leontiev, D. A. (2008). Approbation of the Russian-language versions of two scales developed for the express-assessment of subjective well-being. The 3th All-Russian Sociological Congress Materials. Moscow: The Institute of Sociology RAS, The Russian Society of Sociologists.

Petrides, K. V. \& Furnham, A. (2001). Trait emotional intelligence: Psychometric investigation with reference to established trait taxonomies. European Journal of Personality, 15, 425-448.

Riley, H. \& Schutte, N.S. (2003). Low emotional intelligence as a predictor of substance-use problems. Journal of Drug Education, 33, 391-398.

Rosenberg, M. (1965). Society and the adolescent self-image. Princeton, NJ: Princeton University Press.

Saklofske, D. H., Austin, E. J., \& Minski, P. S. (2003). Factor structure and validity of a trait emotional intelligence measure. Personality and Individual Differences, 34, 707-721.

Salovey, P., \& Grewal, D. (2005). The science of emotional intelligence. Current Directions in Psychological Science, 14, 281-285.

Schutte, N. S. Malouff, J. M., Hall, L. E., Haggerty, D. J., Copper, J. T., Golden, C. J., \& Dornheim, L. (1998). Development and validation of measure of emotional intelligence. Personality and Individual Differences, 25, 167177.

Schutte, N. S., Malouff, J. M., Bobik, C., Coston, T. D., Greeson, C., Jedlicka, C. \& Rhodes, E. W. G. (2001). Emotional intelligence and interpersonal relations. Journal of Social Psychology, 141, 523-536.

Schutte, N. S., Malouff, J. M., Simunek M., McKenley, J., \& Hollander, S. (2002). Characteristic emotional intelligence and emotional well-being. Cognition and Emotion, 16, 769-785.

Schutte, N.S., Malouff, J.M., Thorsteinsson, E.B., Bhullar, N. \& Rooke, S.E., (2007). A meta-analytic investigation of the relationship between emotional intelligence and health. Personality and Individual Differences, 42, 921-933.

Zeidner, M., Matthews, G. \& Roberts, R.D. (2009). What we know about emotional intelligence: how it affects learning, work, relationships, and our mental health. Cambridge, MA: MIT Press. 